Article

\title{
Communication with Local Officials, Self-Efficacy, and Individual Disaster Preparedness: A Case Study of Rural Northwestern China
}

\author{
Junlei Yu ${ }^{1}{ }^{\mathbb{B}}$, Timothy $\mathrm{Sim}^{2}$, Wenhua $\mathrm{Qi}^{3, *}$ and Zhe Zhu ${ }^{1}$ \\ 1 School of Public Management/Emergency Management, Research Center of Emergency Management, \\ Jinan University, Guangzhou 510632, China; junleiyu2015@163.com (J.Y.); zhuchaozhee@126.com (Z.Z.) \\ 2 Department of Applied Social Sciences, The Hong Kong Polytechnic University, Hong Kong 999077, China; \\ timothy.sim@polyu.edu.hk \\ 3 Institute of Geology, China Earthquake Administration, Beijing 100029, China \\ * Correspondence: xiamen1985@163.com; Tel.: +86-10-6200-9028
}

Received: 8 June 2020; Accepted: 30 June 2020; Published: 2 July 2020

check for updates

\begin{abstract}
Promoting individual disaster preparedness is one of the most effective ways to reduce disaster risk. Effective disaster risk communication is widely known to motivate individuals to take protective measures. However, the mechanisms underlying the communication of risk, particularly between local officials and individuals, and its effects on individuals' disaster preparedness are still unclear. This study established a moderated mediation model to investigate the mediating and moderating roles of individuals' level of disaster preparedness knowledge and self-efficacy, respectively, with a focus on local officials as the disaster information source. To test this conceptual model, 1080 villagers from Weinan city, Shaanxi province, China were randomly selected and interviewed. The results showed that frequent interpersonal communication with local officials enhanced villagers' disaster preparedness. However, this relationship was mediated by the extent of villagers' disaster preparedness knowledge. Moderated mediation analysis further indicated that those with a higher level of self-efficacy were more likely to prepare for disasters after receiving disaster risk-reduction information with village officials, but this effect was not significant for villagers with low self-efficacy. These findings indicated that individuals' preparedness level can be increased if local officials regularly communicate disaster risk reduction knowledge to villagers, and that this effect is stronger for individuals with a higher level of self-efficacy.
\end{abstract}

Keywords: government officials; interpersonal communication; disaster risk reduction; disaster preparedness; knowledge; self-efficacy

\section{Introduction}

There is a growing consensus that preparedness at various levels is one of the most effective and economical ways to improve disaster risk reduction (DRR). Significant progress has been made in strengthening disaster preparedness worldwide since the inauguration of the Hyogo Framework for Action 2005-2015: Building the Resilience of Nations and Communities to Disasters (HFA). Continuing the significant progress made over a decade under the HFA, the Sendai Framework for DRR (2015-2030) provided an action-oriented framework to guide DRR practices at all levels [1]. In the Sendai Framework, risk communication was proposed as one of the practical means to promote understanding of disaster risk and preparedness. Risk communication studies have revealed that people tend to seek risk information from various sources, in turn influencing both their intention to adopt and their adoption of preparedness measures [2,3]. Thus, different information sources may 
have different effects on people's disaster preparedness. These roles require in-depth examination to promote disaster risk reduction in the short, medium and long term.

Unidirectional communication sources such as television news programmes may shape the disaster perception and behaviour of some population groups. However, unidirectional communication may play a limited role in long-term disaster preparedness, working only when individuals are exposed to risk information by happenstance (e.g., turning on the television) [4]. Although interpersonal communication may have little direct effect on individual protective behavior [5], risk awareness formed through discussion may help people to better understand their risk environment and improve their daily preparedness [6]. Although information received from interpersonal communication may be less detailed than information in the mass media, people seem to attribute greater trustworthiness to information they receive from others than information they receive from media sources [7].

In China, particularly in rural areas, interpersonal communication may play a particularly large role in DRR, as villagers often have strong supportive social networks developed through farming together, finding work in urban areas together, and even helping each other take care of elderly relatives or children [8]. As these relationships are predicated on mutual trust [9], interpersonal communication in China's rural areas may have an even greater impact than mass media on local people's disaster preparedness. When it comes to interpersonal communication, behavioral scientists have revealed that proximal (e.g., relatives or friends) rather than distal (e.g., emergency officers) people exert the most influence on individuals' decisions to conduct protective actions [10-12]. However, most people do not have a broad sense of risk associated with natural disasters. To compensate for their lack of knowledge, individuals often rely on local officials or experts [13], rather than on their relatives or friends, who they may expect to have a similar level of disaster knowledge. In rural China, local officials represent one of the key sources of disaster risk reduction information for villagers [14]. This is not surprising, as scores for trust in government institutions are much higher in authoritarian political systems like China's than in the democratic systems of the West like the US [15]. Thus, it is interesting to unpack the factors that determine whether and how DRR communication with local officials promotes villagers' disaster preparedness.

This study explores the mediating mechanisms (i.e., in what ways are local officials' communication related to villagers' disaster preparedness?) and moderating mechanisms (i.e., when is the relationship most potent?) underlying the association between local officials' DRR communication and individual disaster preparedness. Confirming these mediating and moderating mechanisms offers critical insights into ways to promote individuals' disaster preparedness and develop effective management measures. We review the literature on the determinants of disaster preparedness, propose a moderated mediation model, and test the model through a stratified sampling household survey in three rural villages with different landforms in Weinan city, Shaanxi province, China. We believe that the findings of this unique empirical study have important implications for stakeholders working on DRR programmes at micro, meso, and macro levels.

\section{Proposed Model}

\subsection{Theoretical Background}

Lindell and Perry (2012) [2] proposed the multi-stage Protective Action Decision Model (PADM) to explain people's responses to environmental hazards and disasters. It suggests that an individual experiences three sequential phases before making a protective decision, namely warning exposure (whether they receive information), attention (whether they heed it), and comprehension (whether they understand it). This process follows with the formation of risk perception, depending heavily on the degree to which an individual's knowledge structure (i.e., the extent of disaster preparedness knowledge). However, people are unlikely to take protective measures if they perceive their ability to cope with the disaster situation in question (self-efficacy) to be low [16]. Therefore, there may be a 
causal chain relating local officials, individual disaster preparedness, disaster preparedness knowledge, and self-efficacy.

\subsection{The Mediating Role of Disaster Preparedness Knowledge}

No single knowledge or information format can encourage individuals to prepare for a disaster, but "interactive information", which derives from interactions with other people, seems to help people to make sense of hazard information [6]. Accordingly, it is logical to assume that interpersonal communication concerning disaster risk may enrich people's disaster preparedness knowledge. As one of the key interpersonal communication sources in rural China, local officials, have been found to play a significant role in increase villagers' risk perception regarding natural hazards [14]. However, whether communicating with local officials enhances villagers' disaster preparedness knowledge requires further exploration.

A lack of knowledge is a barrier to people's preparation for disasters [17]. Studies with diverse methodologies and samples have provided compelling evidence that advanced knowledge promotes disaster preparedness [18-21]. Most research has concurred that receiving disaster information through communication with local officials can increase villagers' preparedness knowledge and further promote actual preparation. However, few studies have directly examined the mediating role of disaster preparedness knowledge in the relation between communicating DRR information with local officials and individual disaster preparedness.

\subsection{The Moderating Role of Self-Efficacy}

Although receiving DRR information during communication with local officials may influence villagers' disaster preparedness, villagers' perceived ability to cope with the negative effects of natural disasters (self-efficacy) is another key issue. People with low self-efficacy may choose not to engage in coping behaviours or may give up quickly because they do not believe that they are capable of achieving their goals [22,23], including communicating with local officials about DRR.

Thus, self-efficacy may moderate the direct relationship between receiving DRR information from local officials and villagers' disaster preparedness. The PADM proposes that individuals with different levels of self-efficacy respond differently to the negative effects of disasters, and that the dynamics of social contexts contribute to people's intended and actual hazard adjustments [2]. Specifically, self-efficacy may either strengthen or damage the relationship between receiving DRR information from local officials and villagers' disaster preparedness.

\subsection{The Present Study}

In this study, we tested a conceptual model (see Figure 1), focused on local officials as an interpersonal communication source that encourages individuals to take disaster preparedness measures. Specifically, the two purposes of this study were (a) to test whether the extent of disaster preparedness knowledge mediates the relationship between receiving DRR information from local officials and villagers' disaster preparedness and (b) to test whether the direct association between local officials as a DRR information source and villagers' preparedness is moderated by villagers' self-efficacy. Together, these two research questions constituted a moderated mediation model (see Figure 1). Based on the literature reviewed above, we put forward the following hypotheses.

Hypothesis 1. Receiving DRR information through communication with local officials increases villagers' disaster preparedness knowledge, which in turn increases their preparedness. That is, disaster preparedness knowledge mediates the link between receiving disaster information from local officials and villagers' preparedness.

Hypothesis 2. Self-efficacy moderates the relationship between receiving disaster information from local officials and villagers' preparedness. This path is stronger when individuals have greater self-efficacy. 


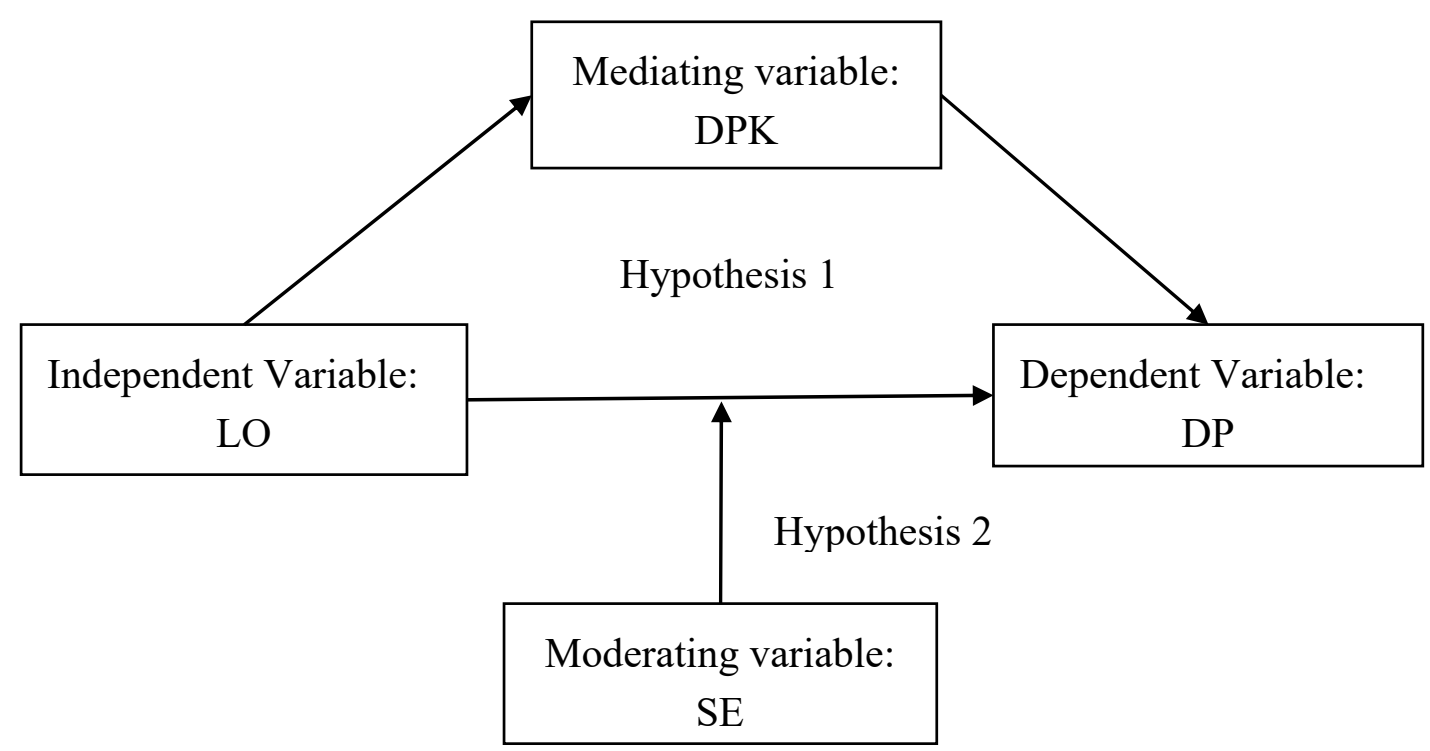

Figure 1. The proposed moderated mediation disaster preparedness model. LO: communicating disaster information from local officials; DPK: disaster preparedness knowledge; SE: self-efficacy; DP: disaster preparedness.

\section{Method}

\subsection{Study Background}

We selected Weinan city in the Chinese province of Shaanxi as our study site. This area has meagre natural resources and highly concentrated poverty in rural settings. Weinan City lies in the eastern part of the Weihe basin, south of the Ordos block of the North China platform, with the active tectonics of the Weihe sub-seismic belt well developed [24]. On 23 January 1556, an earthquake with a magnitude of $8 \frac{1}{4}$ occurred in Shaanxi. This was the deadliest earthquake recorded in world history, with 830,000 casualties. Since 1556, the Weinan City has experienced many earthquakes, including the 1568 Shaanxi Gaoling earthquakes with a magnitude of 7 [25] and several smaller earthquakes with magnitudes of 5 [26]. Even though no destructive earthquake occurred in this area since 1900, earthquake scientists estimated that earthquakes with 7 magnitude are likely to occur within 100 years [24]. Furthermore, this area is also subject to hazards such as drought and flood.

Various disaster education programs and activities have been launched to communicate DRR information with the public in Weinan city. Ways of communicating DRR information include sending out disaster related pamphlets, and answering disaster related questions on spot. However, these activities did not actually promote people's disaster preparedness (according to interviews of local officials by research team members). Thus, how to effectively communicate DRR information with the public requires more in depth exploration.

This study was connected to an international research project. From 2016 to 2019, academic and government agencies from various countries, including China, the UK and the USA, conducted a transdisciplinary project to increase public knowledge of earthquake hazards and enhance the resilience of vulnerable populations living in earthquake hazard-prone regions. From 3 February 2018 to 10 February 2018, the Chinese team conducted a survey to investigate natural hazard risk communication and natural hazard preparedness in Hua district, which is home to the largest number of rural residents in Weinan city. The district is made up of 10 towns, from which we selected three according to both their percentage of residents living in poverty and different landforms. Using data from the Statistics Bureau of Weinan city, one village in a plain area, one in a loess area, and one in a mountain area with the top three largest numbers of poor residents in Hua district were selected (see Figure 2). 


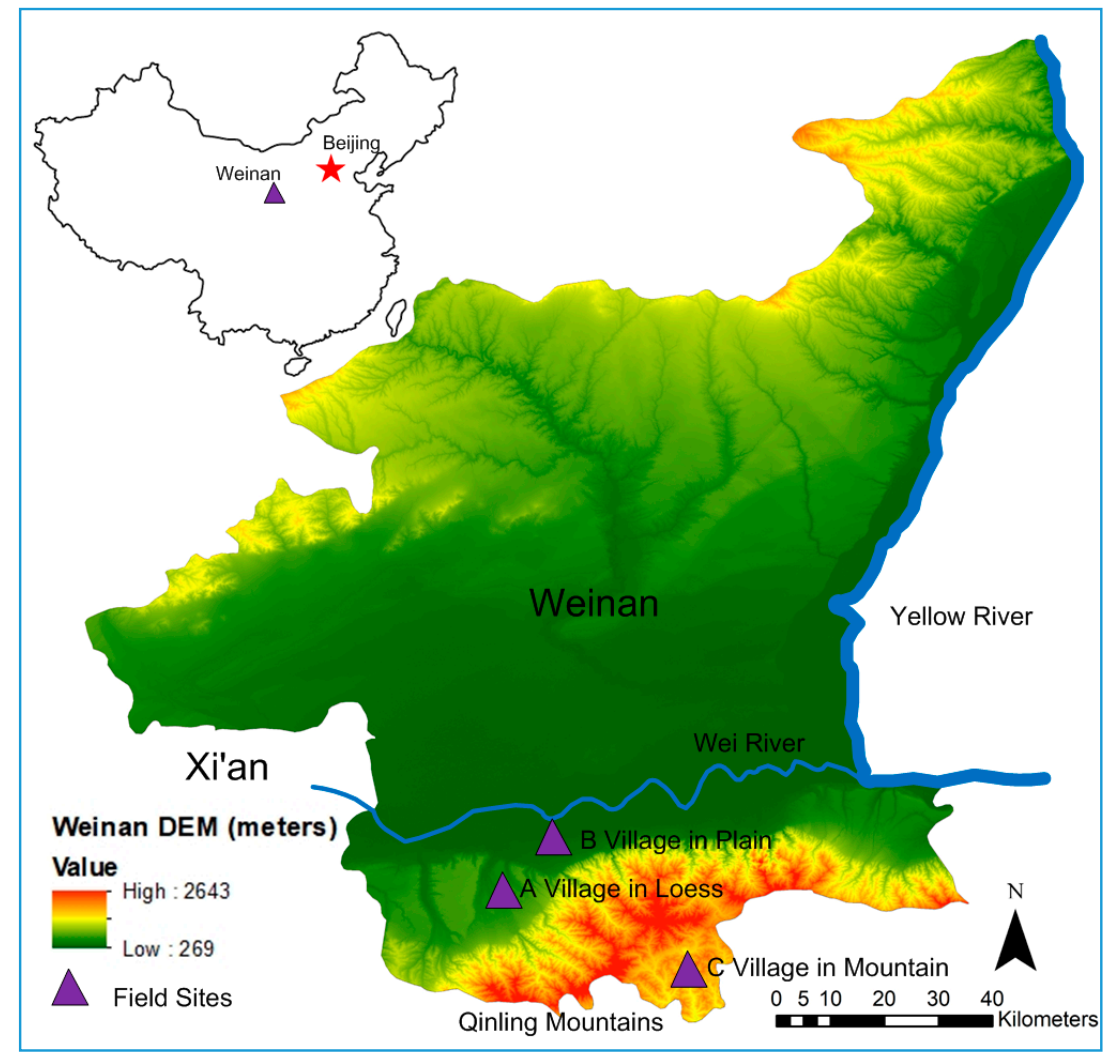

Figure 2. Research area and selected villages.

\subsection{Survey Questions}

The questionnaire consisted of four parts. Interpersonal communication sources and individual disaster preparedness questions were designed based on the national survey on personal preparedness in America conducted by FEMA in 2009 and 2014, respectively [27,28]. The questions were reviewed and adjusted in according to the contexts of this study. According to the definition given by Newnham et al. [23], our research team designed the survey question accordingly.

The first survey question, which focused on interpersonal communication sources of natural hazard information, was "From whom/what do you usually obtain DRR information?" DRR information was defined as information on precursors to and consequences of different types of natural disaster, and possible responses or mitigation measures to be taken should they occur. Based on the literature and consultation with local officials and residents, we identified six sources of information: (1) local officials; (2) relatives, friends, and other villagers; (3) emergency responders; (4) schoolteachers; (5) non-governmental organisations (NGOs); and (6) children who had gained DRR knowledge at school. The respondents were asked to choose "yes" (coded as 1) or "no" (coded as 0 ) in response to each of the items.

To measure the villagers' disaster preparedness, they were asked to answer the following question: "How would you rate your current preparedness for natural disaster that may occur in the near future?" The options were as follows: "I have not considered preparing at all" (coded as 1); "I haven't started to prepare, but am considering doing so within the next six months" (coded as 2); "I have not started to prepare, but I am considering doing so within the next month" (coded as 3); "I will start to prepare soon" (coded as 4); and "I have been prepared for at least six months" (coded as 5).

To measure the respondents' self-efficacy, we also asked, "How confident you are in your ability to take appropriate actions in the first five minutes of a sudden occurrence of natural disaster?" The answers ranged from $1=$ not confident at all to $5=$ very confident. To measure the respondents' level of disaster preparedness knowledge, we asked, "How familiar do you think you are with the 
disaster preparedness concepts?" (i.e., knowing that disaster preparedness involves not only gaining disaster-related knowledge or skills and participating in training or drills, but also stocking up on emergency supplies and making contingency plans). The answers ranged from $1=$ not familiar at all to $5=$ very familiar.

To examine the residents' sociodemographic characteristics, variables such as gender, age, educational attainment, and household size were also included in the questionnaire.

\subsection{Survey Implementation}

Twenty-four locally trained college students who were familiar with the local culture and dialect were engaged to conduct the survey. With the support of local officials and a local NGO, they conducted face-to-face structured interviews with residents of the selected villages. The survey started one week before the Chinese New Year holidays, when most family members gather to prepare for the most important festival of the year. As the selected villages had a large population, stratified sampling was used. Villagers aged 13 years old or above were included in the survey, with both their assent and parental consent obtained where necessary. Ethical approval was sought from the Human Subjects Ethics Application Review System of The Hong Kong Polytechnic University (reference number: HSEARS20180323002).

After eliminating responses with incomplete information on disaster risk communication and preparedness, we examined the interpersonal communication sources, preparedness situation, knowledge, and self-efficacy of 1080 out of 1622 residents.

\subsection{Analyses}

Correlational analyses were conducted to examine the relationships between the four variables after preliminary descriptive analyses had been conducted. A series of regression analyses was conducted to test the mediation effect of disaster preparedness knowledge on the relationship between receiving DRR information from local officials and villagers' disaster preparedness. The PROCESS macro developed by Hayes [29] was used to test the moderation effect of self-efficacy on the relationship between receiving DRR information from local officials and villagers' disaster preparedness. All of the analyses were conducted using SPSS v. 22.

\subsection{Sample Characteristics}

As shown in Table 1, the majority of the respondents were middle-aged (average age: 50). There were more male $(55.3 \%)$ than female respondents, and their education level was relatively low, as only $4.9 \%$ of them were educated to the college level or above. More than two thirds of the respondents shared a household size, with two or three people living together.

Table 1. Sample characteristics $(\mathrm{N}=1080)$.

\begin{tabular}{cccc}
\hline Characteristics & Categories & n/Value & $\%$ \\
\hline \multirow{2}{*}{ Gender } & Male & 597 & $55.3 \%$ \\
& Female & 483 & $44.7 \%$ \\
\hline \multirow{2}{*}{ Educational attainment } & Primary school and lower & 365 & $33.8 \%$ \\
& Junior high school & 516 & $47.8 \%$ \\
& Second high and other technical school & 146 & $13.5 \%$ \\
& College degree and above & 53 & $4.9 \%$ \\
\hline \multirow{2}{*}{ Household size } & One person & 38 & $3.5 \%$ \\
& Two persons & 371 & $34.4 \%$ \\
& Three persons & 342 & $31.7 \%$ \\
& Four persons & 184 & $17.0 \%$ \\
Age & Five persons and above & 145 & $13.4 \%$ \\
\hline
\end{tabular}




\subsection{Descriptive Statistics for DRR Information Source}

When the respondents were asked to name their interpersonal communication sources, the number of those who did not use the sources exceeded the number of those who did for all six sources (see Table 2). Local officials (27.9\%) and relatives, friends, and other villagers (37.9\%) were the two most frequently used interpersonal communication resources. However, based on a preliminary chi-square test, there was no significant relationship between using friends and other villagers as an information source and villagers' disaster preparedness $\left(X^{2}(4,693)=3.45, p=0.48\right)$. In contrast, communication with location officials played a significant role in villagers' disaster preparedness $\left(X^{2}(4,693)=24.65, p<0.01\right)$. However, only a few respondents indicated that they sought information from the other sources, namely emergency responders $(4.6 \%)$, schoolteachers $(5.9 \%)$, NGO staff $(1.1 \%)$, and children had obtained DRR knowledge at school (11.5\%). The following sections present the findings concerning the relationship between local officials as a DRR information communication source and villagers' disaster preparedness.

Table 2. Interpersonal communication sources: descriptive statistics. The numbers in parentheses denote percentages.

\begin{tabular}{ccccccc}
\hline & $\begin{array}{c}\text { Local } \\
\text { Officials }\end{array}$ & $\begin{array}{c}\text { Relatives, } \\
\text { Friends, etc. }\end{array}$ & $\begin{array}{c}\text { Emergency } \\
\text { Responders }\end{array}$ & Schoolteachers & $\begin{array}{c}\text { NGO } \\
\text { Members }\end{array}$ & $\begin{array}{c}\text { Children Learning } \\
\text { DRR Knowledge } \\
\text { from School }\end{array}$ \\
\hline Yes & $301(27.9)$ & $409(37.9)$ & $50(4.6)$ & $64(5.9)$ & $12(1.1)$ & $124(11.5)$ \\
No & $779(72.1)$ & $671(62.1)$ & $1030(95.4)$ & $1016(94.1)$ & $1068(98.9)$ & $956(88.5)$ \\
\hline
\end{tabular}

\section{Results}

The main purposes of this study were to explore whether disaster preparedness knowledge mediates the relationship between receiving disaster information from local officials and villagers' disaster preparedness level, and to examine whether the path between them is moderated by self-efficacy. These research questions were tested in three steps, as follows.

\subsection{Preliminary Analyses}

Means, standard deviation, and zero-order correlations for all of the study variables are presented in Table 3. As expected, those who more frequently obtained disaster information from local officials were more likely to be more confident in their self-efficacy in responding to a sudden occurrence of natural disaster $(\mathrm{r}=0.11, p<0.01)$ and were better prepared $(\mathrm{r}=0.13, p<0.01)$. Those with a higher level of disaster preparedness knowledge were also more confident in their self-efficacy $(r=0.14$, $p<0.01)$ and better prepared $(\mathrm{r}=0.28, p<0.01)$. In addition, individuals with a higher level of self-efficacy were more likely to prepare better for the impact of potential disasters $(r=0.14, p<0.01)$.

Table 3. Descriptive statistics and correlation analysis of the main study variables.

\begin{tabular}{ccccccc}
\hline Variables & $\mathbf{M}$ & $\mathbf{S D}$ & $\mathbf{1}$ & $\mathbf{2}$ & $\mathbf{3}$ & $\mathbf{4}$ \\
\hline 1. LO & 0.28 & 0.45 & 1 & & & \\
2. DPK & 2.03 & 0.97 & 0.06 & 1 & & \\
3. SE & 3.17 & 1.19 & $0.11^{* *}$ & $0.14^{* *}$ & 1 & \\
4. DP & 2.08 & 1.63 & $0.13^{* *}$ & $0.28^{* *}$ & $0.14^{* *}$ & 1 \\
\hline
\end{tabular}

Note. $\mathrm{N}=1080 .{ }^{* *} p<0.01$. LO: receiving DRR information from local officials; DPK: disaster preparedness knowledge; SF: self-efficacy; DP: disaster preparedness.

\subsection{Testing for Mediation Effects}

According to Hypothesis 1, villagers' disaster preparedness knowledge mediates the link between receiving DRR information from local officials and the degree of villagers' disaster preparedness. To examine this hypothesis, this study followed MacKinnon's [30] four-step procedure to establish 
the mediation effect, as follows. (a) A significant relationship between receiving disaster information from local officials and disaster preparedness level. (b) A significant association between receiving disaster information from local officials and level of disaster preparedness knowledge. (c) A significant association between disaster preparedness knowledge and disaster preparedness while controlling for receiving disaster information from local officials. (d) A significant coefficient for the indirect path between receiving disaster information from local officials and disaster preparedness level through adequate disaster preparedness knowledge. The bias-corrected percentile bootstrap method was used to determine whether the last condition was satisfied. To avoid the influence of demographic variables, we controlled for respondents' age, gender, education, and annual income.

The first step in our multiple regression analysis showed that receiving disaster information from local officials was significantly associated with disaster preparedness level: $b=0.15, p<0.01$ (see Model 1 of Table 4 ). In the second step, receiving disaster information from local officials was significantly associated with a higher level of adequate disaster preparedness knowledge: $b=0.08, p<0.05$ (see Model 2 of Table 4). In the third step, when we controlled for receiving disaster information from local officials, disaster preparedness knowledge was significantly associated with disaster preparedness level: $b=0.24, p<0.01$ (see Model 3 of Table 4). Finally, the bias-corrected percentile bootstrap method indicated that the indirect effect was significant: $a b=0.02, S E=0.01,95 \% C I=[0.01,0.03]$. Mediation accounted for $15.4 \%$ of the total effect. Overall, all four criteria for establishing a mediation effect were satisfied. Therefore, Hypothesis 1 was supported.

Table 4. Testing the mediation effect of LO on DP.

\begin{tabular}{ccccccc}
\hline & \multicolumn{2}{c}{ Model 1 (DP) } & \multicolumn{2}{c}{ Model 2 (DPK) } & \multicolumn{2}{c}{ Model 3 (DP) } \\
\cline { 2 - 7 } Predictors & $\boldsymbol{b}$ & $\boldsymbol{t}$ & $\boldsymbol{b}$ & $\boldsymbol{t}$ & $\boldsymbol{b}$ & $\boldsymbol{t}$ \\
\hline LO & 0.15 & $4.91^{* *}$ & 0.08 & $2.65^{*}$ & 0.13 & $4.39^{* *}$ \\
FDP & & & & & 0.24 & $7.95^{* *}$ \\
Age & -0.01 & $-3.62^{* *}$ & -0.01 & $-3.86^{* *}$ & -0.01 & $-2.76^{*}$ \\
Gender & -0.14 & $-2.30^{*}$ & -0.07 & -1.15 & -0.12 & $-2.09^{*}$ \\
Education & 0.08 & $2.41^{*}$ & 0.19 & $5.88^{* *}$ & 0.03 & 1.03 \\
AI & 0.00 & 1.03 & 0.00 & 1.79 & 0.00 & 0.63 \\
R & \multicolumn{2}{c}{0.05} & \multicolumn{2}{c}{0.08} & \multicolumn{2}{c}{0.11} \\
F & \multicolumn{2}{c}{$12.02^{* *}$} & \multicolumn{2}{c}{$19.00^{* *}$} & \multicolumn{2}{c}{$21.4^{* *}$} \\
\hline
\end{tabular}

Note. $\mathrm{N}=848 .{ }^{*} p<0.05 .{ }^{* *} p<0.01$. LO: receiving disaster information from local officials; DPK: extent of disaster preparedness knowledge; SF: self-efficacy; DP: disaster preparedness level; AI: annual income. $b$ : Standardized Coefficient; $t$ : result of $\mathrm{t}$-test.

\subsection{Testing for Moderated Mediation}

Hypothesis 2 predicted that self-efficacy would moderate the direct and indirect associations between receiving disaster information from local officials and disaster preparedness (Figure 1). To examine this moderated mediation hypothesis, we used the PROCESS macro (Model 5) developed by Hayes [29] to test for moderated mediation. As Table 5 demonstrates, receiving disaster information from local officials had a significant main effect on disaster preparedness level: $b=0.11, p<0.01$. Even more importantly, this effect was moderated by self-efficacy: $b=0.09, p<0.01$.

For descriptive purposes, this study plotted disaster preparedness level against village officials for low and high levels of self-efficacy separately (one $S D$ below the mean and one $S D$ above the mean, respectively) (Figure 3). Simple slope tests demonstrated that a higher level of self-efficacy was associated with higher levels of disaster preparedness: $b$ simple $=0.19, p<0.01$. However, a low level of self-efficacy was not significantly associated with disaster preparedness: $b$ simple $=0.02$, $p>0.05$. As self-efficacy only had a significant effect on the high-ranking group, Hypothesis 2 was partially supported. 
Table 5. Testing the moderated mediation effect of LO on DP.

\begin{tabular}{ccc}
\hline Predictors & $\boldsymbol{b}$ & $\boldsymbol{t}$ \\
\hline LO & 0.11 & $3.69^{* *}$ \\
DPK & 0.23 & $7.68^{* *}$ \\
SE & 0.09 & $2.94^{* *}$ \\
VO $\times$ SE & 0.09 & $2.79^{* *}$ \\
Age & -0.01 & $-2.84^{* *}$ \\
Gender & -0.10 & -1.69 \\
Education & 0.04 & 1.09 \\
AI & 0.00 & 0.31 \\
R $^{2}$ & \multicolumn{2}{c}{0.12} \\
F & \multicolumn{2}{c}{$17.94^{* *}$}
\end{tabular}

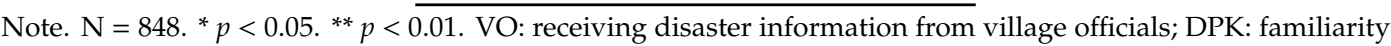
with disaster preparedness knowledge; SF: self-efficacy; DP: disaster preparedness level; AI: annual income. $b$ : Standardized Coefficient; $t$ : result of t-test.

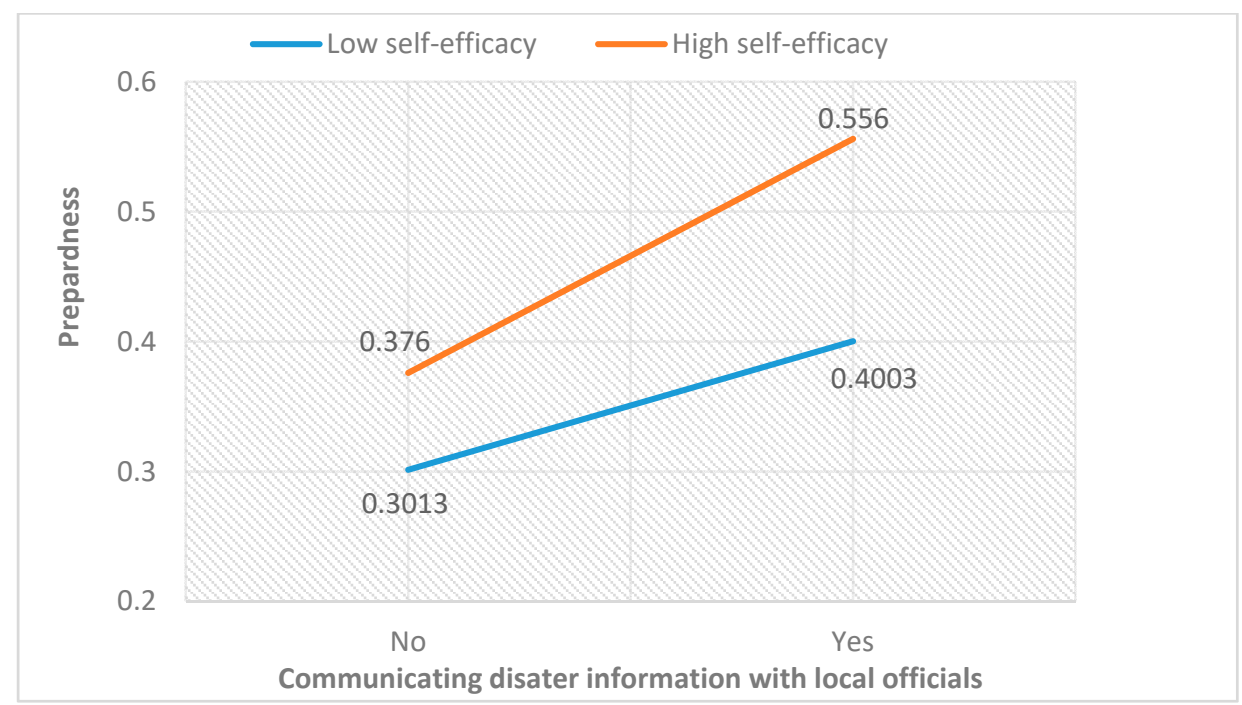

Figure 3. Respondents' disaster preparedness as a function of disaster risk reduction (DRR) information communication with local officials and self-responsibility.

\section{Discussion}

Empirical evidence of the influence of interpersonal communication on disaster preparedness has recently been provided [31,32]. However, questions concerning the underlying mediating and moderating mechanisms remain largely unanswered. This study established a moderated mediation model to test whether the relationship between receiving DRR information from local officials and villagers' disaster preparedness is mediated by villagers' disaster preparedness knowledge and moderated by villagers' self-efficacy. The results indicate that receiving DRR information from local officials increases villagers' knowledge concerning disaster preparedness, which in turn promotes their perceived and actual disaster preparedness. Furthermore, the direct relationship between receiving DRR information from local officials and individuals' disaster preparedness was stronger for individuals with higher self-efficacy. More specifically, a high rather than a low level of self-efficacy was found to promote disaster preparedness. The following sections discuss each of our abovementioned research hypotheses.

\subsection{The Mediating Role of Disaster Preparedness Knowledge}

Regarding the first hypothesis, this study confirmed that disaster preparedness knowledge is mediated by the relationship between local officials as the interpersonal communication source of 
DRR information and villagers' disaster preparedness. That is, individuals with greater disaster preparedness knowledge are more likely to adopt disaster preparedness measures after receiving DRR information from local officials. This finding provides empirical support for the PADM [2], according to which the degree of villagers' hazard knowledge affects the type of protection they seek and the information resources on which they rely. This study echoes several calls to promote individual disaster preparedness through risk communication [33-35]. According to Abunyewah et al. [36], in the past, many risk communication strategies failed to motivate people to prepare for disasters because local authorities were insufficiently persuasive. The results of this study indicate that by providing more disaster preparedness information when communicating with the public, local authorities may be better able to persuade people to prepare well for disaster.

The individual associations in the mediation model are also noteworthy. The first stage of the analysis pertained to local officials as an interpersonal communication source that increases villagers' disaster preparedness knowledge. Our finding is consistent with the results of earlier literature regarding the impact of interpersonal interactions on building knowledge and skills relating to preparedness and response [6]. Gaining such knowledge and skills requires ongoing practice and communication, especially interpersonal communication [37]. Compared with other interpersonal sources (e.g., family members or friends), local authorities seem to gain more trust due to the formal information and professional knowledge they provide [38]. However, fewer than $30 \%$ of respondents in this study indicated that they acquired DRR information from local authorities. This suggests that local authorities in rural Chinese villages should adopt more contextually relevant practices or programmes to communicate with local villagers.

The second stage of the analysis pertained to the relationship between individuals' disaster preparedness knowledge and disaster preparedness. We found that a higher level of disaster preparedness knowledge promoted disaster preparedness, consistent with the results of many other studies $[18,36,39,40]$. This finding has some practical implications for risk communication. For example, risk communication messages and other strategies designed to enhance household preparedness should incorporate approaches that foster preparedness knowledge [21]. However, one of the major challenges to DRR knowledge communication in rural China is its implementation. Rural residents should first be encouraged to obtain disaster-related knowledge. According to the overall mediation results, training local officials to communicate disaster knowledge to villagers would be a good start. However, retaining disaster preparedness knowledge is needed together with awareness creation to motivate people to take preparedness measures towards disaster risks [36]. Even though not discussed in this study, ways to promote individuals' disaster risk awareness after learning disaster related knowledge are essential, which requires further exploration.

\subsection{The Moderating Role of Self-Efficacy}

The second goal of this study was to examine whether the self-efficacy of Chinese rural villagers moderates the direct link between receiving DRR information from local authorities and villagers' preparedness. The results confirmed our hypothesis, which, consistent with former international studies, stated that individuals with a stronger belief in their ability to cope with sudden disturbances to their lives are more likely to engage in protective activities $[16,23,41]$. Our study further confirmed that the process of disaster preparedness does not occur in a stepwise fashion. Becker and colleagues [6] noted that although their household earthquake preparedness model was depicted as linear, the process itself is not strictly linear, as feedback occurs throughout. Our study suggested that people's reception of DRR information, self-efficacy, and disaster preparedness may operate simultaneously and in parallel. Similar findings were reported by Mulis and Duval [42,43], according to whom people's risk perception, coping responsibility, and preparedness are not strictly linear.

Furthermore, our study suggested that the direct relationship between receiving DRR information from local officials and villagers' disaster preparedness is significant for those with a high but not a low level of self-efficacy. According to the person-relative-to-event model, when coping 
resources are appraised as insufficient relative to the threat magnitude, problem-focused coping will decrease even on learning that the threat level is increasing [42]. This suggests that simply providing information on factors such as the likelihood or severity of a future disaster is relatively ineffective in changing self-efficacy or action coping; strategies based on participation and empowerment are more appropriate [16]. Therefore, practices designed to encourage people to engage in DRR management with due consideration of individuals' resources and capacities are needed. In addition to traditional sources of hazard or preparedness education, such as brochures and websites, personal interaction with local officials through school activities, community activities, workplace activities, and training, may be useful [6]. Based on the findings of this study, the goal of these interactive activities should be to enhance people's self-efficacy, which will in turn improve communication between local officials and individuals concerning disaster preparedness.

\section{Limitations}

Our study had several important limitations. First, as a self-reported questionnaire was used to conduct the assessment, the respondents may have over- or under-reported their level of disaster preparedness. Second, like many other studies, this research was clearly limited by the use of solely cross-sectional data. In future research, longitudinal data should be analysed to test this study's findings. Furthermore, our study did not explore how government policy may directly influence villagers' disaster preparedness. China has made considerable progress in improving rural residents' well-being in recent years, but it is unclear how much of this is due to improved DRR policies. Future research should consider using policy factors to analyse the relationship between receiving DRR information from local officials and villagers' disaster preparedness. Moreover, due to the characteristics of studying area, most responders are Han Chinese. Thus, culture diversity analysis was not included in this study. Last but not least, the underlying assumption of the model developed in this study is that local officials have more disaster-related knowledge than villagers. However, this may not be true in reality. Future research should be designed to eliminate these limitations.

\section{Conclusions}

This study presented the results of a randomised survey conducted in three rural villages in northwestern China to explore the mechanism of the relationship between receiving DRR information from local officials and villagers' disaster preparedness. Based on two hypotheses, the effects of disaster preparedness knowledge and self-efficacy were examined and tested using a moderated mediation model.

The study's findings have concrete practical and policy implications for implementing risk reduction strategies in rural China. The model proposed in this study implies that there are two ways to promote villagers' disaster preparedness:

(1) Increasing villager's preparedness knowledge through communicating DRR information with local officials is an important practical approach to encourage disaster preparedness. Launching disaster education-related campaigns and programs by local officials could be a good way. However, risk about hazards is uncertain and has no clear-cut ways of solving, which requires experienced and skillful local officials to lead the programme.

(2) To help villagers to better prepare for disasters, salient policies should be in place for local officials to consider ways of enhancing villagers' sense of self-efficacy in preparing for disasters. Regularly disseminating information about local emergency management officials' effort to reduce local disaster risks may help increase villagers' confidence of coping disasters and further improve their self-efficacy. 
Author Contributions: Conceptualization, J.Y., T.S. and W.Q.; methodology, J.Y.; formal analysis, J.Y., T.S. and W.Q.; investigation, W.Q.; writing-original draft preparation, J.Y.; writing—review and editing, T.S., W.Q. and Z.Z.; funding acquisition, T.S. and W.Q. All authors have read and agreed to the published version of the manuscript.

Funding: This work was collaboratively supported by a UK-China Collaboration project jointly funded by National Natural Science Foundation of China (Ref. 41661134013) and Hong Kong Polytechnic University for the project An Integrative Research Proposal on Promoting Risk-Informed Public Policies for Risk-Resilient Development (Ref.1-ZVHF). It was also supported by the National Natural Science Foundation of China (Ref. 41907397).

Acknowledgments: We would like to express our gratitude to Jun Zhang, Zhongyi Xin, Yuan Tian, Shili Yang, Shidong Bao, Lei Sun and the local university students in Shaanxi province for their kind assistance in the data collection, as well as all the villagers who participated in our survey.

Conflicts of Interest: The authors declare no conflict of interest.

\section{References}

1. United Nations Office for Disaster Risk Reduction (UNDRR). Hyogo Framework for Action 2005-2015: Building the Resilience of Nations and Communities to Disasters. 2005. Available online: https://www. unisdr.org/2005/wcdr/intergover/official-doc/L-docs/Hyogo-framework-for-action-english.pdf (accessed on 20 February 2020).

2. Lindell, M.K.; Perry, R.W. The protective action decision model: Theoretical modifications and additional evidence. Risk Anal. Int. J. 2012, 32, 616-632. [CrossRef]

3. Diakakis, M.; Priskos, G.; Skordoulis, M. Public perception of flood risk in flash flood prone areas of Eastern Mediterranean: The case of Attica Region in Greece. Int. J. Disaster Risk Reduct. 2018, 28, 404-413. [CrossRef]

4. Dunwoody, S.; Neuwirth, K. Coming to terms with the impact of communication on scientific and technological risk judgments. In Risky Business: Communicating Issues of Science, Risk, and Public Policy; Wilkins, L., Patterson, P., Eds.; Greenwood Press: New York, NY, USA, 1991; pp. 11-30.

5. Morton, T.A.; Duck, J.M. Communication and health beliefs: Mass and interpersonal influences on perceptions of risk to self and others. Commun. Res. 2001, 28, 602-626. [CrossRef]

6. Becker, J.S.; Paton, D.; Johnston, D.M.; Ronan, K.R. A model of household preparedness for earthquakes: How individuals make meaning of earthquake information and how this influences preparedness. Nat. Hazards 2012, 64, 107-137. [CrossRef]

7. Arlikatti, S.; Lindell, M.K.; Prater, C.S.; Zhang, Y. Risk area accuracy and hurricane evacuation expectations of coastal residents. Environ. Behavior. 2006, 38, 226-247. [CrossRef]

8. Wei, J.; Han, Y. Pre-disaster social capital and disaster recovery in Wenchuan earthquake-stricken rural communities. Sustainability 2018, 10, 2046. [CrossRef]

9. Chen, Y.F.; Kang, Y.; Tjosvold, D. Constructive controversy and guanxi relationships for disaster recovery. Int. J. Confl. Manag. 2017, 28, 410-436. [CrossRef]

10. Pearson, M.; Hamilton, K. Investigating driver willingness to drive through flooded waterways. Accid. Anal. Prev. 2014, 72, 382-390. [CrossRef]

11. Hamilton, K.; Peden, A.E.; Pearson, M.; Hagger, M.S. Stop there's water on the road! Identifying key beliefs guiding people's willingness to drive through flooded waterways. Saf. Sci. 2016, 89, 308-314. [CrossRef]

12. Hamilton, K.; Demant, D.; Peden, A.E.; Hagger, M.S. A systematic review of human behaviour in and around floodwater. Int. J. Disaster Risk Reduct. 2020, 47, 101561. [CrossRef]

13. Huang, L.; Ban, J.; Sun, K.; Han, Y.; Yuan, Z.; Bi, J. The influence of public perception on risk acceptance of the chemical industry and the assistance for risk communication. Saf. Sci. 2013, 51, 232-240. [CrossRef]

14. Sim, T.; Hung, L.S.; Su, G.W.; Cui, K. Interpersonal communication sources and natural hazard risk perception: A case study of a rural Chinese village. Nat. Hazards 2018, 94, 1307-1326. [CrossRef]

15. White, J.D.; Fu, K.W. Who do you trust? Comparing people-centered communications in disaster situations in the United States and China. J. Comp. Policy Anal. Res. Pract. 2012, 14, 126-142. [CrossRef]

16. Paton, D.; Smith, L.; Johnston, D. When good intentions turn bad: Promoting natural hazard preparedness. Aust. J. Emerg. Manag. 2005, 1, 25-30.

17. Lindell, M.K.; Arlikatti, S.; Prater, C.S. Why people do what they do to protect against earthquake risk: Perceptions of hazard adjustment attributes. Risk Anal. Int. J. 2009, 29, 1072-1088. [CrossRef] [PubMed]

18. Lindell, M.K.; Perry, R.W. Household adjustment to earthquake hazard: A review of research. Environ. Behave. 2000, 32, 461-501. [CrossRef] 
19. Heath, R.L.; Lee, J.; Palenchar, M.J.; Lemon, L.L. Risk communication emergency response preparedness: Contextual assessment of the protective action decision model. Risk Anal. 2018, 38, 333-344. [CrossRef]

20. Lam, R.P.K.; Leung, L.P.; Balsari, S.; Hsiao, K.; Newnham, E.; Patrick, K.; Pham, P.; Leaning, J. Urban disaster preparedness of Hong Kong residents: A territory-wide survey. Int. J. Disaster Risk Reduct. 2017, 23, 62-69. [CrossRef]

21. Thomas, T.N.; Leander-Griffith, M.; Harp, V.; Cioffi, J.P. Influences of preparedness knowledge and beliefs on household disaster preparedness. Morb. Mortal. Wkly. Rep. 2015, 64, 965-971. [CrossRef]

22. Meilstrup, C.; Thygesen, L.C.; Nielsen, L.; Koushede, V.; Cross, D.; Holstein, B.E. Does self-efficacy mediate the association between socioeconomic background and emotional symptoms among schoolchildren? Int. J. Public Health 2016, 61, 505-512. [CrossRef]

23. Newnham, E.A.; Balsari, S.; Lam, R.P.K.; Kashyap, S.; Pham, P.; Chan, E.Y.; Patrick, K.; Leaning, J. Self-efficacy and barriers to disaster evacuation in Hong Kong. Int. J. Public Health 2017, 62, 1051-1058. [CrossRef] [PubMed]

24. Rodgers, J.; Su, G.W.; Qi, W.H.; Milledge, D.; Densmore, A.; Davis, C.; England, P.; Young, J.; Cao, Y.; Chakos, A.; et al. Creating an earthquake scenario in China: A case study in Weinan city, Shaanxi province. Int. J. Disaster Risk Reduct. 2020, 42, 101305. [CrossRef]

25. Ma, J.; Feng, X.J.; Li, G.Y.; Li, X.N. New insights from analysis of historical texts on the 1568 Northeast Xi'an earthquake, Shaanxi, China. Int. J. Disaster Risk Reduct. 2020, 44, 101417. [CrossRef]

26. IGPCEA (Institute of Geophysics, China Earthquake Administration). Atlas of Historical Earthquakes, Ming Dynasty; China Cartographic Publishing House: Beijing, China, 1986. (In Chinese)

27. FEMA. Personal Preparedness in America: Findings from the Citizen Corps National Survey. 2009. Available online: https://www.fema.gov/media-library-data/20130726-1859-25045-2081/2009_citizen_corps_national_ survey_findings__full_report.pdf (accessed on 26 June 2020).

28. FEMA. Preparedness in America: Research Insights to Increase Individual, Organizational, and Community Action. 2014. Available online: https://www.fema.gov/media-library-data/14090008880261e8abc820153a6c8cde24ce42c16e857/20140825_Preparedness\%20in\%20America_August\%202014\%20Update_ 508.pdf (accessed on 26 June 2020).

29. Hayes, A.F. Introduction to Mediation, Moderation, and Conditional Process Analysis: A Regression-Based Approach, 2nd ed.; Guilford Press: New York, NY, USA, 2017.

30. MacKinnon, D. Introduction to Statistical Mediation Anal; Routledge: New York, NY, USA, 2012.

31. Kim, Y.C.; Kang, J. Communication, neighbourhood belonging and household hurricane preparedness. Disasters 2010, 34, 470-488. [CrossRef]

32. Shepherd, J.; van Vuuren, K. The Brisbane flood: CALD gatekeepers' risk communication role. Disaster Prev. Manag. 2014, 23, 469-483. [CrossRef]

33. Rowan, K.E. Goals, obstacles, and strategies in risk communication: A problem-solving approach to improving communication about risks. J. Appl. Commun. Res. 1991, 19, 300-329. [CrossRef]

34. Paton, D. Disaster preparedness: A social-cognitive perspective. Disaster Prev. Manag. Int. J. 2003, 12, 210-216. [CrossRef]

35. Höppner, C.; Buchecker, M.; Bründl, M. Risk Communication and Natural Hazards; CapHaz Project: Birmensdorf, Switzerland, 2010.

36. Abunyewah, M.; Gajendran, T.; Maund, K. Conceptual framework for motivating actions towards disaster preparedness through risk communication. Procedia Eng. 2018, 212, 246-253. [CrossRef]

37. Engelberg, M.; Flora, J.A.; Nass, C.I. AIDS knowledge: Effects of channel involvement and interpersonal communication. Health Commun. 1995, 7, 73-91. [CrossRef]

38. Kirschenbaum, A.A.; Rapaport, C.; Canetti, D. The impact of information sources on earthquake preparedness. Int. J. Disaster Risk Reduct. 2017, 21, 99-109. [CrossRef]

39. Gaillard, J.C.; Mercer, J. From knowledge to action: Bridging gaps in disaster risk reduction. Prog. Hum. Geogr. 2013, 37, 93-114. [CrossRef]

40. Weichselgartner, J.; Pigeon, P. The role of knowledge in disaster risk reduction. Int. J. Disaster Risk Sci. 2015, 6, 107-116. [CrossRef]

41. Becker, J.S.; Paton, D.; Johnston, D.M.; Ronan, K.R. Salient beliefs about earthquake hazards and household preparedness. Risk Anal. 2013, 33, 1710-1727. [CrossRef] [PubMed] 
42. Mulilis, J.P.; Duval, T.S. The PrE model of coping and tornado preparedness: Moderating effects of responsibility. J. Appl. Soc. Psychol. 1997, 27, 1750-1766. [CrossRef]

43. Mulilis, J.P.; Duval, T.S. Activating effects of resources relative to threat and responsibility in person-relative-to-event theory of coping with threat: An educational application 1. J. Appl. Soc. Psychol. 2003, 33, 1437-1456. [CrossRef] 